14. Daniels HE. Rank correlation and population models. $J$ R Stat Soc Series B 1950;12:171-181.

15. Mann HB. Non-parametric tests against trend. Econometrica 1945; 113:245-259.

16. Conover WJ. Practical Nonparametric Statistics. 2nd ed. New York, NY: John Wiley \& Sons; 1980.

17. Kachigan SK. Statistical Analysis: An Interdisciplinary Introduction to Univariate and Multivariate Methods. New York, NY: Radius Press; 1986.

18. Frome EL, Kutner MH, Beauchamp JJ. Regression analysis of Poisson-distributed data. J Am Stat Assoc 1973;68:935-940.

19. Frome EL. The analysis of rates using Poisson regression models. Biometrics 1983;39:665-674.

20. Frome EL, Checkoway H. Use of Poisson regression models in estimating incidence rates and ratios. Am J Epidemiol 1985;121:309-323

21. McCullagh P, Nelder JA. Generalized Linear Models. 2nd ed. London, England: Chapman Hall; 1989.

22. Draper N, Smith H. Applied Regression Analysis. 2nd ed. New York, NY: John Wiley \& Sons; 1981.

23. Campbell MJ, Machin D, D'Arcangues C. Coping with extraPoisson variability in the analysis of factors influencing vaginal ring expulsions. Stat Med 1991;10:241-254.

24. Bartko JJ. The negative binomial distribution: a review of properties and applications. Va J Science 1961;12:18-37.

25. Fisher RA. The negative binomial distribution. Ann Eugenics 1941;11:182-187.
26. Gallus G, Radaelli G, Marchi M. Poisson approximation to a negative binomial process in the surveillance of rare health events. Methods Inf Med 1991;30:206-209.

27. Kianifard F, Gallo PP. Poisson regression analysis in clinical research. J Biopharm Stat 1995;5:115-129.

28. Lawless JF. Negative binomial and mixed Poisson regression. Can J Stat 1987;15:209.

29. Rumke CL. How long is the wait for an uncommon event? J Chronic Dis 1982;35:561-564.

30. Tripathi RC. Negative binomial distribution. In: Kotz S, Johnson NL, eds. Encyclopedia of Statistical Sciences. Vol 6. New York, NY: John Wiley \& Sons; 1985:169-177.

31. Hosmer DW, Lemeshow S. Applied Logistic Regression. New York, NY: John Wiley \& Sons; 1989.

32. Hosmer DW, Taber S, Lemeshow S. The importance of assessing the fit of logistic regression models: a case study. $A m \mathrm{~J}$ Public Health 1991;81:1630-1635.

33. Ely JW, Dawson JD, Mehr DR, Burns TL. Understanding logistic regression analysis through example. Fam Med 1996;28:134-140.

34. Berry G. The analysis of mortality by the subject-years method. Biometrics 1983;39:173-184.

35. Fuller WA. Introduction to Statistical Time Series. New York, NY: John Wiley \& Sons; 1989.

36. Kleinbaum DG, Kupper LL, Morgenstern H. Epidemiologic Research: Principles and Quantitative Methods. New York, NY: Van Nostrand Reinhold; 1982:32-34.

\title{
Usefulness of Clinical Predictors for TB Isolation
}

\section{Gina Pugliese, RN, MS; Martin S. Favero, PhD}

Respiratory isolation places an enormous financial burden on hospitals that care for a substantial number of patients with tuberculosis (TB) and, in particular, public hospitals, which care for most of these patients in the United States.

Grady Memorial Hospital, a public hospital in Atlanta, cares for approximately 200 patients with active TB each year. An expanded respiratory isolation policy was implemented recently that resulted in a dramatic reduction in exposure episodes (from 4.4 to 0.6 episodes per month) and an accompanying reduction in tuberculin skin-test conversion rates in healthcare workers. The expanded policy made respiratory isolation mandatory for all patients with active $\mathrm{TB}$, with TB in the differential diagnosis, or with acid-fast bacilli (AFB) sputum smears and cultures ordered, as well as for all HIV-infected patients with abnormal chest radiographs until three sputum smears negative for AFB were obtained. The expanded respiratory isolation policy resulted in appropriate isolation of more than 95\% of patients with TB on admission, but also resulted in an eightfold overuse of isolation rooms. Researchers at Grady Memorial sought to modify this policy to reduce unnecessary admission to isolation by evaluating the usefulness of clinical information available to admitting physicians for predicting active TB. Clinical findings in 295 patients admitted to respiratory isolation during a 3-month period were evaluated for their usefulness in determining which patients had TB. Multivariate analysis identified five predictive variables, including chest radiograph with upper lobe infiltrate or cavity, self-reported positive tuberculin skin test, and self-reported isoniazid preventive therapy. Using these variables to develop a hypothetical policy to determine which patients required isolation would have decreased the number of isolated non-TB patients during the study period from 253 to 95 , but it would have missed 8 of the 42 patients with TB.

The authors note that the strongest predictors of active TB among all patients admitted to respiratory isolation was chest radiographic findings of an upper lobe infiltrate or pulmonary cavity. However, stratifying by HIV serostatus eliminated this association for patients who were HIV seropositive, findings consistent with numerous other reports.

The authors conclude that the low sensitivity of the hypothetical policy made it an unacceptable alternative for their hospital. They suggest that further work is needed to identify clinical predictors that would decrease overuse of isolation beds while maintaining satisfactory sensitivity for patients with TB.

FROM: Bock NN, McGowan JE, Ann J, Tapia J, Blumberg HM. Clinical predictors of tuberculosis as a guide for a respiratory isolation policy. $A m \mathrm{~J}$ Respir Crit Care Med 1996;154:14681472. 